BMJ Open

Diabetes

Research

\& Care

\title{
Real-world clinical outcomes following treatment intensification with GLP-1 RA, OADs or insulin in patients with type 2 diabetes on two oral agents (PATHWAY 2-OADs)
}

\author{
Cyrus Desouza (D) , ${ }^{1}$ Andreas R Kirk, ${ }^{2}$ Kamal K Mangla, ${ }^{3}$ Michael L Wolden, ${ }^{2}$ \\ Ildiko Lingvay (D) 4
}

To cite: Desouza C, Kirk AR, Mangla KK, et al. Real-world clinical outcomes following treatment intensification with GLP-1 RA, OADs or insulin in patients with type 2 diabetes on two oral agents (PATHWAY 2-OADs). BMJ Open Diab Res Care 2020;8:e001830. doi:10.1136/ bmjdrc-2020-001830

- Supplemental material is published online only. To view, please visit the journal online (http://dx.doi.org/10.1136/ bmjdrc-2020-001830).

Received 17 August 2020 Revised 16 November 2020 Accepted 17 November 2020

Check for updates

(c) Author(s) (or their employer(s)) 2020. Re-use permitted under CC BY-NC. No commercial re-use. See rights and permissions. Published by BMJ.

For numbered affiliations see end of article.

Correspondence to Dr Cyrus Desouza; cdesouza@unmc.edu

\section{ABSTRACT}

Introduction Most patients with type 2 diabetes require sequential addition of glucose-lowering agents to maintain long-term glycemic control. In this retrospective, observational study, we compared intensification with a glucagon-like peptide-1 receptor agonist (GLP-1 RA), oral antidiabetic drugs (OADs), and insulin in patients receiving two OADs, using US electronic health records and claims data.

Research design and methods For inclusion, patients in the IBM MarketScan Explorys database were required to have claims for two different OADs in the 180-day baseline period and $\geq 1$ claim for a different OAD/GLP-1 RA/insulin at index date (treatment intensification). Changes in glycated hemoglobin $\left(\mathrm{HbA}_{1 \mathrm{c}}\right)$ and weight from baseline were assessed at 180 days postindex. Patients were propensity scorematched by baseline characteristics and exact-matched by $\mathrm{HbA}_{1 \mathrm{c}}$ category $\left(\mathrm{HbA}_{1 \mathrm{c}}\right.$ cohort and weight/composite outcomes cohort) and body mass index (BMI) category (weight/composite outcomes cohort only) to obtain balanced treatment arms. The primary endpoint was the percentage of patients reaching target $\mathrm{HbA}_{1 \mathrm{c}}<7 \%(53 \mathrm{mmol} / \mathrm{mol})$. Results Significantly more patients intensifying with a GLP-1 RA achieved $\mathrm{HbA}_{1 \mathrm{c}}<7 \%$ than those receiving $\mathrm{OAD}(\mathrm{s})$ (OR: $1.35 ; 95 \% \mathrm{Cl} 1.03$ to $1.77 ; \mathrm{p}=0.032$ ) or insulin (OR: $1.77 ; 95 \% \mathrm{Cl} 1.27$ to $2.47 ; p<0.001)$. GLP-1 RAs were also associated with a significantly greater chance of not gaining weight; significantly greater $\mathrm{HbA}_{1 \mathrm{c}}$ and weight decreases from baseline; and a significantly greater chance of $\mathrm{HbA}_{1 \mathrm{c}}<7 \%$, no weight gain and discontinuation of $\geq 1$ baseline OAD (composite outcome), compared with $\mathrm{OAD}(\mathrm{s})$ or insulin.

Conclusions In propensity score-matched cohorts, GLP-1 RAs demonstrated significant benefits for both glycemic control and weight management over additional $\mathrm{OAD}(\mathrm{s})$ or insulin, respectively, indicating that they may represent the optimal choice at these points in the treatment pathway.

\section{INTRODUCTION}

Achieving glycemic control is a major treatment aim in type 2 diabetes, and maintenance of glycated hemoglobin $\left(\mathrm{HbA}_{1 \mathrm{c}}\right)$ at or below target levels is associated with reductions in the risk of long-term complications. ${ }^{12}$ Weight

\section{Significance of this study}

What is already known about this subject?

- For patients with type 2 diabetes receiving two oral antidiabetic drugs (OADs) who require treatment intensification to maintain glycemic control, physicians may prescribe a third oral agent, a glucagonlike peptide-1 receptor agonist (GLP-1 RA) or insulin.

What are the new findings?

- Compared with either additional $\mathrm{OAD}(\mathrm{s})$ or insulin, GLP-1 RAs are associated with significantly greater chances of meeting a glycated hemoglobin $\left(\mathrm{HbA}_{1 \mathrm{c}}\right)$ target of $<7 \%$, of not gaining weight, and of achieving both these outcomes while discontinuing at least one baseline OAD.

- GLP-1 RAs are also associated with significantly greater $\mathrm{HbA}_{1 \mathrm{c}}$ and weight decreases from baseline than either additional $\mathrm{OAD}(\mathrm{s})$ or insulin.

How might these results change the focus of research or clinical practice?

- These results suggest that GLP-1 RAs may represent the optimal treatment choice for patients receiving two OADs, providing benefits in terms of glycemic control, weight management and baseline medication discontinuation.

management is both a treatment aim and a key consideration in improving glycemic control. ${ }^{3}$ However, in most cases, long-term maintenance of glycemic control requires sequential addition of multiple glucoselowering agents. ${ }^{4}$

The standard of care for type 2 diabetes in recent years has been to use metformin as a first-line therapy, followed by treatment intensification with additional oral antidiabetic drugs (OADs), commonly sulfonylureas (SUs) or dipeptidyl peptidase-4 inhibitors (DPP-4is). ${ }^{4}$ However, clinicians have multiple 
options for patients requiring treatment intensification. Decisions are based on various considerations, including risk of hypoglycemia, weight management, side effects, comorbidities and patient preference, which is often influenced by administration route and convenience of treatment. ${ }^{4}$ The American Diabetes Association (ADA) guidelines emphasize the importance of timely treatment intensification for achieving glycemic control and recommend that treatment be assessed every 3-6 months, ${ }^{4}$ creating frequent opportunities for healthcare providers to consider intensification options.

Consequently, treating physicians require robust evidence that takes into account all factors informing the decisions made in clinical practice, as a complement to data from randomized controlled trials (RCTs). Welldesigned, real-world studies can identify large, diverse cohorts that are representative of patients at specific points in the therapeutic pathway, yielding comparative effectiveness data for different intensification options. Patients' experiences with treatment can also be examined using these data sources, by assessing medicationtaking behavior.

We designed the retrospective, observational PATHWAY study (Comparison of Treatment Intensification Options on Health Outcomes and Persistency for Real World T2DM Patients at Early and Late Stages of OAD Treatment) to identify optimal therapeutic options for patients with type 2 diabetes at different treatment intensification stages, making use of linked US electronic healthcare records (EHR) and administrative claims data. In this analysis, PATHWAY 2-OADs, we have focused on treatment intensification with additional $\operatorname{OAD}(\mathrm{s})$, a glucagon-like peptide-1 receptor agonist (GLP-1 RA) or insulin in patients receiving two OADs (online supplemental figure 1). This comparison reflects a common treatment decision in clinical practice during the time that our study was conducted: it would be expected that most patients receive metformin plus DPP-4is or SUs, with injectable therapies considered as an alternative to a third OAD when further intensification is required, as shown in another recent analysis of treatment intensification in US patients receiving two OADs. ${ }^{5}$ Here, we assess $\mathrm{HbA}_{1 \mathrm{c}}$ and weight outcomes, discontinuation of baseline OADs, and adherence to and persistence with intensification treatment.

\section{RESEARCH DESIGN AND METHODS}

\section{Data source}

We used data from the IBM MarketScan Explorys Linked Claims-EHR Database (IBM Watson Health, Armonk, New York, USA), which combines anonymized EHR with inpatient and outpatient administrative claims from commercially insured patients. ${ }^{6}$ Available data include medical history, prescriptions, clinical events, and laboratory tests from more than 50 million unique patients across all care settings, representing approximately $15 \%$ of the US population. Linkage to MarketScan allows confirmation that patients collected their prescriptions. ${ }^{7}$ At the time of the analysis, more than 500000 patients included in the entire database had at least one code for type 2 diabetes.

\section{Study design and patient population}

This was a retrospective, observational study, with index period from March 1, 2013 to October 31, 2018. For inclusion, patients aged 18 years or older are required to have been continuously enrolled in the database for 180 days each side of treatment intensification (index date (day 0 ); figure 1). Patients are required to have at least one International Classification of Diseases (ICD)-9 or ICD-10 $\operatorname{code}^{89}$ associated with type 2 diabetes any time before or on the index date. Those who had a code associated with type 1 diabetes or secondary diabetes preindex or gestational diabetes or pregnancy during the study period (September 1, 2012-October 31, 2018), were excluded.

Patients who intensified treatment were identified as those with at least one claim (indicating a prescription fill, typically for 30 or 90 days' medication) for each of two OADs in different classes in the 180 days preindex (baseline period), and at least one claim for any other OAD (in a different class from baseline OADs), GLP-1 RA or insulin at index date. Patients who received treatments in only one $\mathrm{OAD}$ class (including those who switched treatments within a class) or more than two OAD classes before treatment intensification, or had one or more claims for injectables or index treatment during the baseline period, were excluded. Patients who initiated fixed dose combinations as index treatment were defined by the treatment class of the novel agent. For example, in a patient with a metformin claim in the baseline period who initiated metformin+DPP-4i at treatment intensification date, DPP-4i was considered to be the index treatment. Patients with claims for more than one index treatment on two different dates were included in the cohort corresponding to the earliest claim; those with claims for more than one index treatment on the same date were excluded.

\section{Outcomes}

We assessed $\mathrm{HbA}_{1 \mathrm{c}}$ reduction and weight reduction at 6 months after treatment intensification (day 180) for GLP-1 RA versus OAD (s) and for GLP-1 RA versus insulin. To maximize the available sample sizes, we analyzed separate cohorts for $\mathrm{HbA}_{1 \mathrm{c}}$ and weight/composite outcomes. Patients with eligible $\mathrm{HbA}_{1 \mathrm{c}}$ and weight measurements were included in both cohorts. Baseline $\mathrm{HbA}_{1 \mathrm{c}}$ and weight were taken as the measurements within the baseline period closest to the treatment intensification date, between day -180 and day 15 for $\mathrm{HbA}_{1 \mathrm{c}}$, and between day -180 and day 0 for weight. Follow-up measurements were those closest to day 180 ( \pm 90 days (days $91-270)$ for both $\mathrm{HbA}_{1 \mathrm{c}}$ and weight; figure 1).

Patients who discontinued baseline OADs were identified via claims captured in the 6 months after treatment 


\section{SECONDARY USE OF DATA}

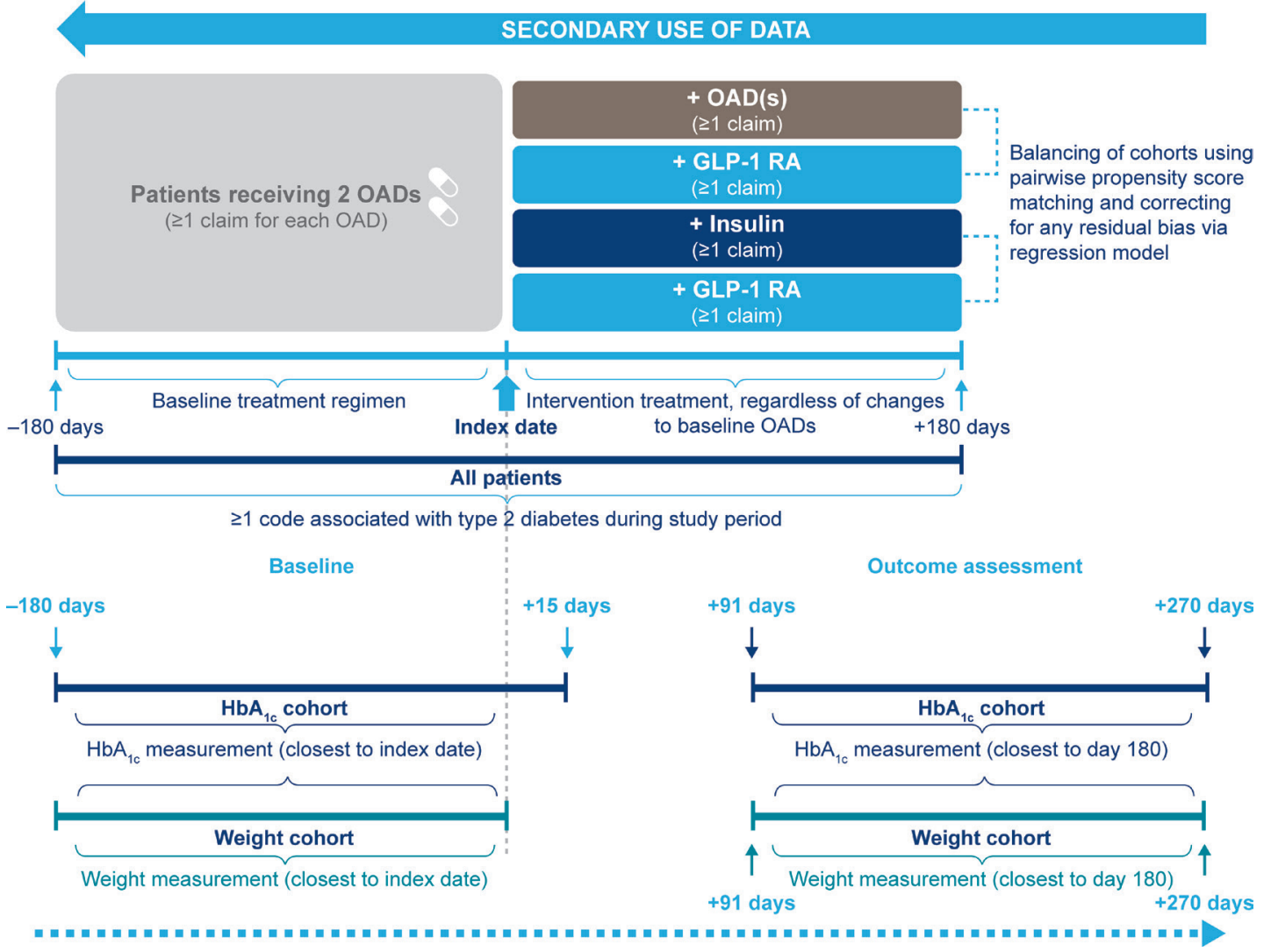

Figure 1 Study design. Index date was defined as the date of treatment intensification. GLP-1 RA, glucagon-like peptide-1 receptor agonist; $\mathrm{HbA}_{1 \mathrm{c}}$, glycated hemoglobin; $\mathrm{OAD}$, oral antidiabetic drug.

intensification (follow-up period) in the $\mathrm{HbA}_{1 c}$ cohort. Patients with at least one claim for a given baseline OAD were assumed to have continued receiving this therapy in addition to index treatment; those with no claims were assumed to have discontinued the respective baseline OAD.

The primary endpoint was the percentage of patients reaching target $\mathrm{HbA}_{1 \mathrm{c}}<7 \%(53 \mathrm{mmol} / \mathrm{mol})$. We also assessed the percentages of patients with no weight gain and those who achieved weight loss $\geq 3 \%$, and calculated the mean absolute $\mathrm{HbA}_{1 \mathrm{c}}$ and weight changes from baseline for each treatment cohort. To reflect the multiplicity of factors that are considered when selecting treatment intensification options- $\mathrm{HbA}_{1 \mathrm{c}}$, weight and patient preference for fewer medications-we assessed the percentages of patients meeting three composite endpoints:

- Target $\mathrm{HbA}_{1 \mathrm{c}}<7 \%$ (53 $\mathrm{mmol} / \mathrm{mol}$ ) with no weight gain.

- Target $\mathrm{HbA}_{1 \mathrm{c}}<7 \%$ (53 mmol $/ \mathrm{mol}$ ) with discontinuation of one or more baseline OADs.

- Target $\mathrm{HbA}_{1 \mathrm{c}}<7 \%$ (53 mmol/mol) with no weight gain and discontinuation of one or more baseline OADs.

For each endpoint, we calculated the OR for the GLP-1 RA cohort versus the $\mathrm{OAD}(\mathrm{s})$ cohort and the insulin cohort.

\section{Adherence and persistence}

Adherence to and persistence with intensification treatment over the 180-day follow-up period were assessed in the $\mathrm{HbA}_{1 c}$ cohort. Our approach was aligned with best practice guidance for assessing medication-taking behavior in claims databases. ${ }^{10}$ Adherence was summarized as the mean proportion of days covered (PDC); adherent patients were those with PDC $\geq 0.8$ during follow-up. Persistence was summarized as the mean stay time in the full cohorts and as the time to discontinuation for patients who discontinued treatment. Stay time was defined as the treatment period in days from index date until discontinuation (see online supplemental methods) or end of follow-up, with a maximum allowable gap of 60 days. The percentage of patients who persisted with treatment over the entire 180-day period was also calculated.

The date of treatment discontinuation was either the last treatment day (last fill+days' supply associated with the last fill), if there were no further claims in the 60 days following this date, or day of initiation of new antidiabetic medication class (not baseline or index medication) after the last fill, whichever was the earliest. In the $\mathrm{OAD}(\mathrm{s})$ cohort, switching treatment to a different OAD class was considered to be index treatment discontinuation. 


\section{Propensity score matching}

In non-randomized studies, propensity score (PS) matching is used to obtain patient cohorts that are balanced in terms of their baseline characteristics, controlling for confounding in estimating treatment effects. ${ }^{11}$ In our analyses, matching was performed separately for each comparison (GLP-1 RA vs OAD(s), GLP-1 RA vs insulin). Patients were exact-matched by baseline $\mathrm{HbA}_{1 \mathrm{c}}$ category to obtain $\sim 0 \%$ standardized mean differences (SMD) between treatment arms. In the weight/ composite outcomes cohort, patients were also exactmatched by BMI category. Following exact matching, patients were matched pairwise on up to 33 baseline demographic and clinical characteristics, including age, sex, weight, $\mathrm{HbA}_{1 c}$, comorbidities and baseline antidiabetic medications (see online supplemental methods).

Matching method was chosen based on the number of patients available after matching and the SMD between comparators, which was required to be $\leq 10 \%$. For the OAD(s) and GLP-1 RA cohorts, optimal matching with a 1:1 ratio and default 0.25 caliper was used; for the insulin and GLP-1 RA cohorts, a greedy nearest neighbor method with a 1:1 ratio and 0.1 caliper was used.

\section{Statistical analyses}

For demographic and clinical characteristics and outcome metrics, mean and SD were calculated for continuous variables. Counts and percentages were calculated for categorical variables.

In line with established methods to control for any remaining confounding variables following PS matching, ${ }^{12}$ further adjustment for significant baseline covariates was applied in statistical analyses (see online supplemental methods). The differences between cohorts in terms of changes in $\mathrm{HbA}_{1 c}$ and weight were estimated using analysis of covariance, ORs were estimated using logistic regression, and HRs were estimated using a Cox proportional hazard model. The OAD(s) and insulin cohorts were used as the reference cohorts for the GLP-1 RA cohort in the respective comparisons.

\section{RESULTS}

Study population and baseline characteristics

In total, 183882 patients with type 2 diabetes initiating at least one antidiabetic medication were identified. Of this group, 102771 had continuous enrollment either side of the index date and met none of the exclusion criteria, of whom 23467 had at least one claim for each of two OADs in the baseline period. A total of 4792 patients had the requisite $\mathrm{HbA}_{1 \mathrm{c}}$ measurements, and 3927 patients had both $\mathrm{HbA}_{1 \mathrm{c}}$ and weight measurements. Online supplemental table 1 shows the number of these patients receiving each index treatment, before and after matching. In the matched cohorts, all patients had a record of type 2 diabetes diagnosis before index date, with the exception of one patient in the GLP-1 RA versus $\mathrm{OAD}(\mathrm{s})$ analysis and two patients in the GLP-1 RA versus insulin analysis, for whom diagnosis and index date were the same. As these patients met the condition of receiving two $\mathrm{OAD}(\mathrm{s})$ in the baseline period, it is assumed that this is due to a delay in recording type 2 diabetes diagnosis.

There were prematching disparities in some baseline characteristics across the cohorts; for example, the mean $\mathrm{HbA}_{1 \mathrm{c}}$ was higher in the insulin cohorts (online supplemental table 2 and online supplemental table 3). Following PS matching, these characteristics were well balanced (table 1 and online supplemental table 4 ). In the $\mathrm{HbA}_{1 \mathrm{c}}$ cohorts, the mean age was 56.0 years for GLP-1 RA versus $\mathrm{OAD}(\mathrm{s})$, and 57.2/57.6 years for GLP-1 RA versus insulin. Approximately $50 \%$ of patients in each cohort were women. The mean BMI was between $35 \mathrm{~kg} / \mathrm{m}^{2}$ and $37 \mathrm{~kg} / \mathrm{m}^{2}$, and the mean weight was between $104.1 \mathrm{~kg}$ and $107.4 \mathrm{~kg}$. Exact matching by baseline $\mathrm{HbA}_{1 \mathrm{c}}$ category resulted in closely matched cohorts, with SMD of approximately $0 \%$ for baseline $\mathrm{HbA}_{1 \mathrm{c}}$. There was a relatively low prevalence of cardiovascular disease $(2.8 \%-4.5 \%$ across cohorts). Baseline characteristics were similar for the weight/composite outcome cohorts.

Across the $\mathrm{HbA}_{1 \mathrm{c}}$ and weight/composite outcomes cohorts, the most common combinations of baseline OADs were metformin plus SU $(42.2 \%-50.5 \%)$ and metformin plus DPP-4i (26.2\%-32.4\%; table 1 and online supplemental table 4). To confirm that two OADs were taken at the same time, we assessed days covered and showed that, on average, each patient received two OADs simultaneously for 100 days during the baseline period. For treatment intensification in the $\mathrm{HbA}_{1 \mathrm{c}}$ cohorts, the most common GLP-1 RAs used were liraglutide (49.5\%$49.6 \%)$, exenatide extended release $(22.1 \%-22.5 \%)$ and dulaglutide (19.6\%-20.0\%; online supplemental figure $2)$. No patients in the analyses had received injectable or oral semaglutide, because their availability did not overlap with the study period or meet the inclusion criterion requiring 180 days of follow-up. The most common OADs used were DPP-4is $(30.9 \%)$, SUs $(25.1 \%)$ and sodium-glucose co-transporter-2 inhibitors (22.3\%). The vast majority of the patients who intensified treatment with insulin received a long-acting form $(83.2 \%)$, with only $5.5 \%$ receiving rapid-acting insulin and $4.3 \%$ receiving both long-acting and rapid-acting insulin. A similar pattern was observed in the weight/composite outcomes cohorts.

\section{$\mathrm{HbA}$, reduction from baseline}

ORs, $95 \%$ CIs, and numbers and percentages of patients achieving single and composite outcomes are presented in figure 2. Absolute changes from baseline are presented in online supplemental figure 3 and online supplemental table 6 .

\section{GLP-1 RA versus $0 A D(s)$}

In total, $38.3 \%$ of patients intensifying treatment with GLP-1 RA and $32.1 \%$ of those intensifying with OAD(s) reached an $\mathrm{HbA}_{1 \mathrm{c}}$ target of $<7 \%(53 \mathrm{mmol} / \mathrm{mol})$, equating to an OR of 1.35 in favor of GLP-1 RA (95\% CI 1.03 to 1.77; 
Table 1 Postmatching baseline characteristics for the $\mathrm{HbA}_{1 \mathrm{c}}$ cohort

\begin{tabular}{|c|c|c|c|c|c|c|}
\hline & \multirow{2}{*}{$\begin{array}{l}\text { OAD(s) } \\
n=530\end{array}$} & \multirow{2}{*}{$\begin{array}{l}\text { GLP-1 RA } \\
n=530\end{array}$} & \multirow[b]{2}{*}{ SMD } & \multirow{2}{*}{$\begin{array}{l}\text { Insulin } \\
\mathrm{n}=398\end{array}$} & \multirow{2}{*}{$\begin{array}{l}\text { GLP-1 RA } \\
n=398\end{array}$} & \multirow[b]{2}{*}{ SMD } \\
\hline & & & & & & \\
\hline Age, years & $56.0(10.7)$ & $56.0(9.7)$ & 0.00 & $57.6(11.0)$ & $57.2(9.8)$ & -0.04 \\
\hline Sex (male/female), \% & $48.7 / 51.3$ & $49.8 / 50.2$ & $0.02 /-0.02$ & $49.2 / 50.8$ & $53.3 / 46.7$ & $0.08 /-0.08$ \\
\hline BMI, $\mathrm{kg} / \mathrm{m}^{2}$ & $36.2(7.1)$ & $36.7(7.2)$ & 0.07 & $35.6(6.9)$ & $35.7(6.7)$ & 0.01 \\
\hline Weight, kg & $105.3(23.3)$ & $107.4(24.5)$ & 0.09 & $104.1(22.9)$ & $105.4(24.1)$ & 0.05 \\
\hline $\mathrm{HbA}_{1 \mathrm{c}}, \%$ & $8.5(1.5)$ & $8.5(1.5)$ & -0.01 & $8.9(1.5)$ & $8.9(1.6)$ & 0.02 \\
\hline $\mathrm{HbA}_{1 \mathrm{c}}, \mathrm{mmol} / \mathrm{mol}^{*}$ & $69(16.6)$ & $69(16.7)$ & - & $74(16.5)$ & $74(16.9)$ & - \\
\hline $\begin{array}{l}\text { Adapted Diabetes Complications Severity Index } \\
\text { score }^{16}\end{array}$ & $0.58(1.04)$ & $0.52(0.99)$ & -0.06 & $0.65(1.09)$ & $0.60(1.07)$ & -0.05 \\
\hline Quan-Charlson Comorbidity Index score ${ }^{1718}$ & $0.65(1.13)$ & $0.62(0.97)$ & -0.03 & $0.71(1.18)$ & $0.69(1.01)$ & -0.01 \\
\hline \multicolumn{7}{|l|}{ Baseline antidiabetic medication, \% } \\
\hline AGI & 0.4 & 0.2 & -0.04 & 0.8 & 0.3 & -0.07 \\
\hline Biguanide (metformin) & 87.4 & 88.9 & 0.05 & 85.4 & 86.9 & 0.04 \\
\hline DPP-4i & 38.5 & 37.0 & -0.03 & 37.4 & 37.7 & 0.01 \\
\hline D2 dopamine receptor agonist & 0.0 & 0.2 & 0.06 & 0.0 & 0.3 & 0.07 \\
\hline Insulin-sensitizing agent (TZD) & 7.9 & 8.9 & 0.03 & 8.5 & 6.3 & -0.09 \\
\hline Meglitinide & 0.4 & 0.6 & 0.03 & 1.0 & 0.8 & -0.03 \\
\hline SGLT-2i & 12.8 & 12.3 & -0.02 & 6.5 & 7.0 & 0.02 \\
\hline SU & 52.6 & 52.1 & -0.01 & 60.3 & 60.8 & 0.01 \\
\hline \multicolumn{7}{|l|}{ Baseline OAD combination, \% } \\
\hline Metformin+SU & 43.2 & 44.3 & - & 48.2 & 50.5 & - \\
\hline Metformin+DPP-4i & 30.4 & 27.5 & - & 26.9 & 26.6 & - \\
\hline Metformin+SGLT-2i & 7.9 & 10.2 & - & 4.5 & 5.5 & - \\
\hline Metformin+TZD & 5.5 & 6.6 & - & 5.3 & 3.8 & - \\
\hline DPP-4i+SU & 4.9 & 6.2 & - & 8.5 & 8.3 & - \\
\hline Others & 8.1 & 5.1 & - & 6.5 & 5.3 & - \\
\hline \multicolumn{7}{|l|}{ Comorbidities (selected), \% } \\
\hline Hyperlipidemia & 67.5 & 65.1 & -0.05 & 66.6 & 66.1 & -0.01 \\
\hline Hypertension & 65.5 & 63.4 & -0.04 & 67.3 & 66.8 & -0.01 \\
\hline Obesity & 27.9 & 25.5 & -0.06 & 22.6 & 20.9 & -0.04 \\
\hline Depression & 11.3 & 11.7 & 0.01 & 12.6 & 11.8 & -0.02 \\
\hline Diabetic neuropathy & 10.9 & 10.8 & -0.01 & 11.3 & 12.3 & 0.03 \\
\hline Anxiety & 6.8 & 5.7 & -0.05 & 4.8 & 4.3 & -0.02 \\
\hline Diabetic nephropathy & 5.8 & 4.3 & -0.07 & 6.8 & 5.8 & -0.04 \\
\hline Renal & 5.5 & 4.7 & -0.03 & 6.8 & 6.5 & -0.01 \\
\hline Cerebrovascular & 3.4 & 2.5 & -0.06 & 3.3 & 3.0 & -0.01 \\
\hline Diabetic retinopathy & 3.2 & 4.3 & 0.06 & 4.8 & 4.5 & -0.01 \\
\hline Stroke/TIA & 3.2 & 2.3 & -0.06 & 3.0 & 2.8 & -0.01 \\
\hline Peripheral vascular disease & 3.0 & 2.6 & -0.02 & 3.0 & 3.3 & 0.01 \\
\hline Cardiovascular & 2.8 & 3.4 & 0.03 & 3.8 & 4.5 & 0.04 \\
\hline \multicolumn{7}{|l|}{ Type of payer, \% } \\
\hline Commercial & 84.0 & 84.9 & 0.03 & 81.7 & 80.7 & -0.03 \\
\hline Medicare & 16.0 & 15.1 & -0.03 & 18.3 & 19.3 & 0.03 \\
\hline \multicolumn{7}{|l|}{ Health plan, \% } \\
\hline Preferred provider organization & 50.0 & 49.6 & -0.01 & 41.2 & 45.7 & 0.09 \\
\hline Comprehensive & 12.8 & 12.1 & -0.02 & 14.8 & 13.3 & -0.04 \\
\hline Health maintenance organization & 12.6 & 13.4 & 0.02 & 17.3 & 15.1 & -0.06 \\
\hline
\end{tabular}

Continued 


\begin{tabular}{|c|c|c|c|c|c|c|}
\hline & \multirow{2}{*}{$\begin{array}{l}\text { OAD(s) } \\
n=530\end{array}$} & \multirow{2}{*}{$\begin{array}{l}\text { GLP-1 RA } \\
n=530\end{array}$} & \multirow[b]{2}{*}{ SMD } & \multirow{2}{*}{$\begin{array}{l}\text { Insulin } \\
\mathrm{n}=398\end{array}$} & \multirow{2}{*}{$\begin{array}{l}\text { GLP-1 RA } \\
n=398\end{array}$} & \multirow[b]{2}{*}{ SMD } \\
\hline & & & & & & \\
\hline Consumer-driven health plan & 9.2 & 9.1 & -0.01 & 9.0 & 8.8 & -0.01 \\
\hline Other/unknown & 15.3 & 15.8 & - & 17.6 & 17.1 & - \\
\hline
\end{tabular}

Data are mean (SD) except where otherwise stated.

The Adapted Diabetes Complications Severity Index is based on a scale ranging from 0 to 2 for each complication as follows: $0=$ no abnormality, $1=$ some abnormality, $2=$ severe abnormality. Each patient receives one score from each of the seven complication categories. The higher score is used when a patient has more than one condition in a given category. After summing scores from all seven categories, a patient may have a total score from 0 to a maximum of 13.

The Quan-Charlson Comorbidity Index score is computed by adding the weights that are assigned to the specific diagnoses. Each diagnosis is only counted once. The minimum possible score is 0 and the maximum possible score is 24 .

Cardiovascular comorbidities were congestive heart failure, acute or old myocardial infarction, and stable or unstable angina.

Renal comorbidities included chronic kidney disease, end-stage renal disease, renal failure, renal osteodystrophy, kidney transplant and dialysis. *Matching performed for $\mathrm{HbA}_{1 \mathrm{c}}$ expressed as percentages only.

AGI, alpha-glucosidase inhibitor; BMI, body mass index; DPP-4i, dipeptidyl peptidase-4 inhibitor; GLP-1 RA, glucagon-like peptide-1 receptor agonist; $\mathrm{HbA}_{10}$, glycated hemoglobin; OAD, oral antidiabetic drug; SGLT-2i, sodium-glucose co-transporter-2 inhibitor; SMD, standardized mean difference; SU, sulfonylurea; TIA, transient ischemic attack; TZD, thiazolidinedione.

$\mathrm{p}=0.032$; figure $2 \mathrm{~A})$. This increased to $48.2 \%$ vs $34.5 \%$ (OR: 2.03; $95 \%$ CI 1.41 to $2.92 ; \mathrm{p}<0.001$ ) in patients who were adherent to medication postintensification.

Overall, treatment intensification with either a GLP-1 RA or OAD(s) was associated with mean absolute reductions from baseline in $\mathrm{HbA}_{1 \mathrm{c}}$ of $-1.0 \%(-10.4 \mathrm{mmol} /$ $\mathrm{mol})$ and $-0.7 \%(-7.8 \mathrm{mmol} / \mathrm{mol})$, respectively, with a $-0.25 \%(-2.7 \mathrm{mmol} / \mathrm{mol})$ reduction in favor of GLP-1 RA ( $p=0.001)$. The difference between treatments was more pronounced in a subgroup of patients who were adherent to treatment postintensification (GLP-1 RA: $\mathrm{n}=278,-1.3 \%(-13.7 \mathrm{mmol} / \mathrm{mol}) ; \mathrm{OAD}(\mathrm{s}): \mathrm{n}=313,-0.8 \%$ $(-8.6 \mathrm{mmol} / \mathrm{mol}) ;-0.41 \%(-4.5 \mathrm{mmol} / \mathrm{mol})$ in favor of GLP-1 RA; $\mathrm{p}<0.001)$.

\section{GLP-1 RA versus insulin}

In total, $32.7 \%$ of those who intensified treatment with GLP-1 RA and $22.9 \%$ of those intensifying with insulin reached an $\mathrm{HbA}_{1 \mathrm{c}}$ target of $<7 \%(53 \mathrm{mmol} / \mathrm{mol})$, equating to an OR for GLP-1 RA versus insulin of 1.77 (95\% CI 1.27 to 2.47 ; $\mathrm{p}<0.001$; figure $2 \mathrm{~B}$ ). This increased to $41.9 \%$ vs $23.9 \%$ (OR: $2.39 ; 95 \%$ CI 1.47 to 3.89 ; $\mathrm{p}<0.001$ ) in patients who were adherent to medication (figure 2B).

Treatment intensification with GLP-1 RA was associated with a significantly greater mean absolute reduction from baseline in $\mathrm{HbA}_{1 \mathrm{c}}$, compared with insulin $(-1.3 \%$ $(-14.0 \mathrm{mmol} / \mathrm{mol})$ and $-0.8 \%(-8.6 \mathrm{mmol} / \mathrm{mol})$, respectively; $-0.45 \%(-4.9 \mathrm{mmol} / \mathrm{mol})$ in favor of GLP-1 RA; $\mathrm{p}<0.001)$, including in patients who were adherent to treatment postintensification (GLP-1 RA: $\mathrm{n}=215,-1.6 \%$ $(-17.2 \mathrm{mmol} / \mathrm{mol})$ reduction; insulin: $\mathrm{n}=142,-0.9 \%$ $(-9.8 \mathrm{mmol} / \mathrm{mol})$ reduction; $-0.5 \%(-5.5 \mathrm{mmol} / \mathrm{mol})$ in favor of GLP-1 RA; $\mathrm{p}<0.001$ ).

\section{Weight reduction from baseline GLP-1 RA versus $O A D(s)$}

Consistently greater percentages of those receiving GLP-1 RAs at treatment intensification achieved no weight gain and $\geq 3 \%$ weight loss, versus patients receiving $\mathrm{OAD}(\mathrm{s})$. This equated to ORs of 2.10 and 1.72 in favor of GLP-1
RA versus $\mathrm{OAD}(\mathrm{s})$ for each respective endpoint $(\mathrm{p}<0.001$; figure $2 \mathrm{~A}$ ). In patients who were adherent to treatment, the OR for no weight gain was 2.71 in favor of GLP-1 RA versus $\mathrm{OAD}(\mathrm{s})$.

Treatment intensification with a GLP-1 RA rather than $\mathrm{OAD}(\mathrm{s})$ resulted in significantly greater weight loss from baseline (GLP-1 RA: $-2.4 \mathrm{~kg}(-2.2 \%)$; OAD(s): $-0.7 \mathrm{~kg}(-0.6 \%) ;-1.7 \mathrm{~kg}$ in favor of GLP-1 RA; $\mathrm{p}<0.001)$, including in patients who were adherent to treatment (GLP-1 RA: $-2.8 \mathrm{~kg}(-2.4 \%)$; OAD(s): $-0.7 \mathrm{~kg}(-0.5 \%)$; $-2.3 \mathrm{~kg}$ in favor of GLP-1 RA; $\mathrm{p}<0.001$ ).

\section{GLP-1 RA versus insulin}

Significantly greater percentages of those receiving GLP-1 RAs at treatment intensification achieved no weight gain and $\geq 3 \%$ weight loss versus patients receiving insulin, with ORs of 3.67 and 2.95 in favor of GLP-1 RAs for each respective endpoint $(p<0.001$; figure $2 \mathrm{~B})$. In patients who were adherent to treatment, the OR for no weight gain was 4.40 in favor of GLP-1 RA versus insulin.

Treatment intensification with a GLP-1 RA was associated with significant reductions in weight from baseline, whereas intensification with insulin resulted in a small mean gain (GLP-1 RA: $-2.4 \mathrm{~kg}(-2.3 \%)$; insulin: $+0.05 \mathrm{~kg}$ $(+0.3 \%) ;-2.5 \mathrm{~kg}$ in favor of GLP-1 RA; $<<0.001)$. This pattern was replicated in patients who were adherent to treatment (GLP-1 RA: $-2.5 \mathrm{~kg}(-2.3 \%)$; insulin: $+0.04 \mathrm{~kg}$ $(+0.3 \%) ;-2.7 \mathrm{~kg}$ in favor of GLP-1 RA; $\mathrm{p}<0.001)$.

\section{Baseline OAD discontinuation}

Full data on the percentages of patients discontinuing each baseline $\mathrm{OAD}$ in the $\mathrm{HbA}_{1 \mathrm{c}}$ cohort are shown in online supplemental table 5 .

\section{GLP-1 RA versus $0 A D(s)$}

In total, $43.2 \%$ of those receiving a GLP-1 RA discontinued at least one of their baseline OADs, compared with $29.2 \%$ of those who intensified treatment with additional $\mathrm{OAD}(\mathrm{s})$, equating to an OR of 1.91 (95\% CI 1.48 to 2.48; $\mathrm{p}<0.001$; figure $2 \mathrm{~A}$ ). 
A

B

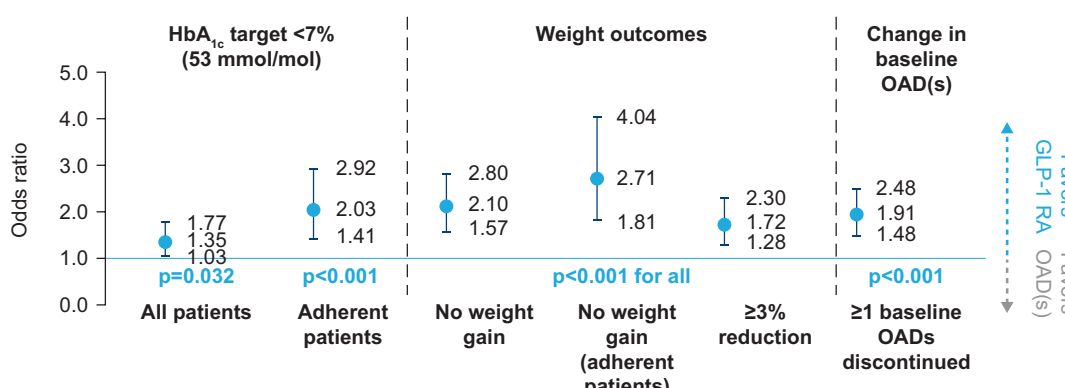

\begin{tabular}{|l|c|c|c|c|c|c|}
\hline OAD(s), & $170 / 530$ & $108 / 313$ & $246 / 429$ & $150 / 270$ & $114 / 429$ & $155 / 530$ \\
n/N (\%) & $(32.1)$ & $(34.5)$ & $(57.3)$ & $(55.6)$ & $(26.6)$ & $(29.2)$ \\
\hline GLP-1, & $203 / 530$ & $134 / 278$ & $315 / 429$ & $168 / 223$ & $164 / 429$ & $229 / 530$ \\
n/N (\%) & $(38.3)$ & $(48.2)$ & $(73.4)$ & $(75.3)$ & $(38.2)$ & $(43.2)$ \\
\hline
\end{tabular}

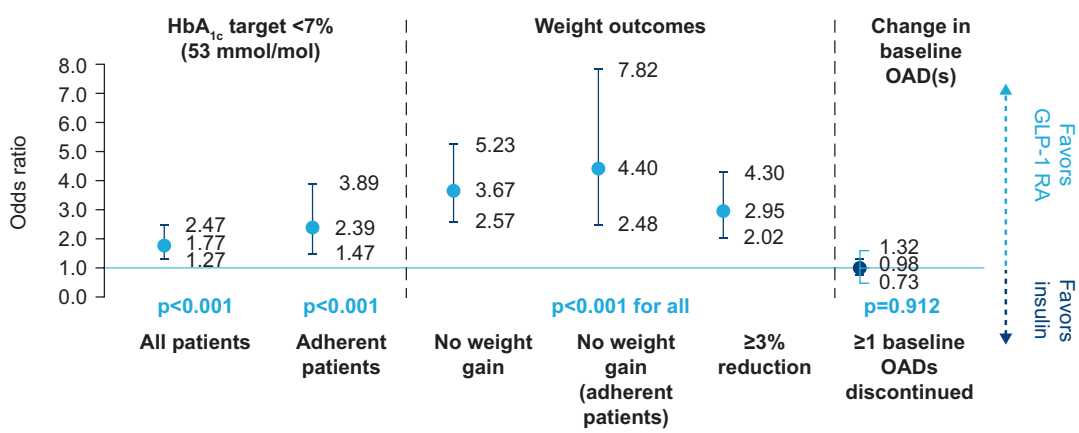

\begin{tabular}{|l|c|c|c|c|c|c|}
\hline Insulin, & $91 / 398$ & $34 / 142$ & $134 / 298$ & $48 / 105$ & $54 / 298$ & $161 / 398$ \\
n/N (\%) & $(22.9)$ & $(23.9)$ & $(45.0)$ & $(45.7)$ & $(18.1)$ & $(40.5)$ \\
\hline GLP-1, & $130 / 398$ & $90 / 215$ & $221 / 298$ & $121 / 160$ & $116 / 298$ & $161 / 398$ \\
n/N (\%) & $(32.7)$ & $(41.9)$ & $(74.2)$ & $(75.6)$ & $(38.9)$ & $(40.5)$ \\
\hline
\end{tabular}

C

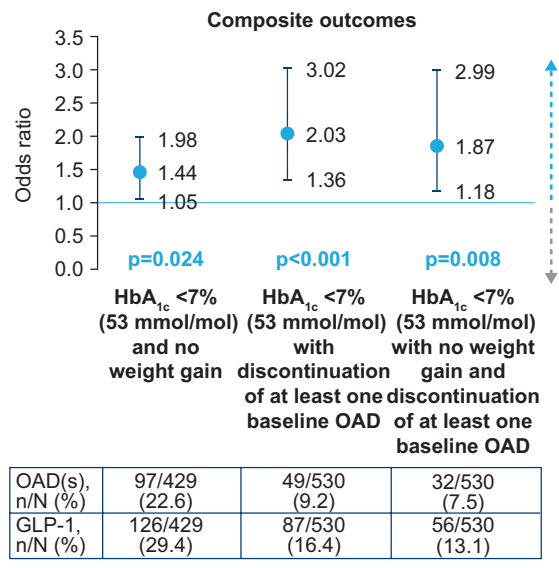

D

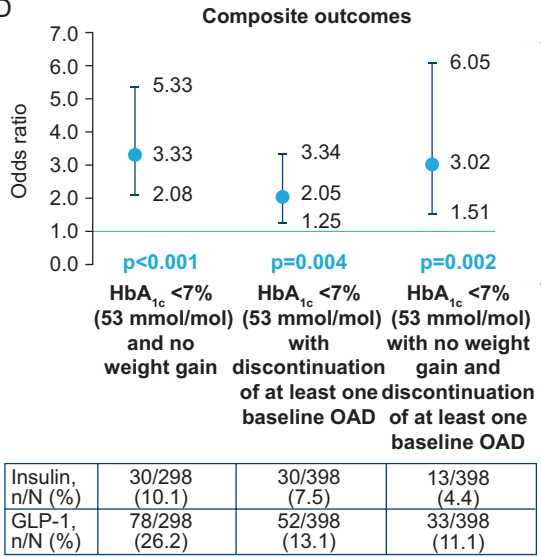

discontinuation of at least one baseline OAD (OR: 2.03; $95 \%$ CI 1.36 to $3.02 ; \mathrm{p}<0.001$ ), and of achieving $\mathrm{HbA}_{1 \mathrm{c}}<7 \%$ (53 mmol/mol) with no weight gain and discontinuation of at least one baseline OAD (OR: $1.87 ; 95 \%$ CI 1.18 to $2.99 ; \mathrm{p}=0.008)$.

\section{GLP-1 RA versus insulin}

Patients who intensified treatment with a GLP-1 RA were significantly more likely to achieve $\mathrm{HbA}_{1 \mathrm{c}}<7 \%$ (53 mmol $/ \mathrm{mol}$ ) and no weight gain (OR: 3.33; 95\% CI 2.08 to 5.33 ; $<<0.001), \mathrm{HbA}_{1 \mathrm{c}}<7 \%(53 \mathrm{mmol} / \mathrm{mol})$ with discontinuation of at least one baseline OAD (OR: $2.05 ; 95 \%$ CI 1.25 to $3.34 ; \mathrm{p}=0.004$ ), and $\mathrm{HbA}_{1 \mathrm{c}}$ $<7 \%$ (53 mmol $/ \mathrm{mol}$ ) with no weight gain and discontinuation of at least one baseline OAD (OR: 3.02; 95\% GLP-1 RA. Patients in this cohort also had a greater chance of achieving $\mathrm{HbA}_{1 \mathrm{c}}<7 \%(53 \mathrm{mmol} / \mathrm{mol})$ with 
Table 2 Adherence and persistence over 180 days postindex for GLP-1 RAs versus OAD(s) and versus insulin

\begin{tabular}{|c|c|c|c|c|}
\hline \multirow{2}{*}{$\begin{array}{l}\text { GLP-1 RA vs OAD(s) } \\
\text { Criteria }\end{array}$} & \multirow{2}{*}{$\begin{array}{l}\text { OAD(s) } \\
\text { All }(n=530)\end{array}$} & \multicolumn{3}{|l|}{ GLP-1 RA } \\
\hline & & All $(n=530)$ & OD $(n=263)$ & OW $(n=239)$ \\
\hline \multicolumn{5}{|l|}{ Adherence } \\
\hline PDC, mean (SD) & $0.75(0.27)$ & $0.71(0.27)$ & $0.66(0.28)$ & $0.74(0.28)$ \\
\hline Adherent patients (PDC $\geq 0.80), \mathrm{n}(\%)$ & $313(59.1)$ & $278(52.5)$ & $110(41.8)$ & $146(61.1)$ \\
\hline OR $(95 \% \mathrm{Cl})$ vs OADs & - & $0.76(0.60$ to 0.98$)$ & 0.51 (0.38 to 0.69$)$ & $1.09(0.80$ to 1.49$)$ \\
\hline$P$ value & - & 0.0316 & $<0.001$ & 0.60 \\
\hline \multicolumn{5}{|l|}{ Persistence } \\
\hline Stay time, days, mean (SD) & $146.0(56.1)$ & $142.4(57.0)$ & $135.5(59.8)$ & $146.6(54.8)$ \\
\hline HR $(95 \% \mathrm{Cl})$ vs OADs & - & $1.16(0.94$ to 1.42$)$ & $1.36(1.10$ to 1.73$)$ & $1.02(0.78$ to 1.34$)$ \\
\hline$P$ value & - & 0.16 & 0.014 & 0.88 \\
\hline Log rank $p$ value & - & 0.15 & 0.0048 & 0.87 \\
\hline Persistent patients, n (\%) & $358(67.5)$ & $338(63.8)$ & $151(57.4)$ & $162(67.8)$ \\
\hline \multicolumn{5}{|l|}{ Discontinuation } \\
\hline Patients who discontinued, n (\%) & $172(32.5)$ & $192(36.2)$ & $112(42.6)$ & $77(32.2)$ \\
\hline Time to discontinuation, days, ${ }^{*}$ mean (SD) & $75.3(47.7)$ & $76.3(45.7)$ & $75.5(46.0)$ & $76.3(44.7)$ \\
\hline GLP-1 RA vs insulin & Insulin & GLP-1 RA & & \\
\hline Criteria & All $(n=398)$ & All $(n=398)$ & OD $(n=197)$ & OW $(n=177)$ \\
\hline \multicolumn{5}{|l|}{ Adherence } \\
\hline PDC, mean (SD) & $0.63(0.29)$ & $0.72(0.27)$ & $0.68(0.27)$ & $0.74(0.28)$ \\
\hline Adherent patients (PDC $\geq 0.80), \mathrm{n}(\%)$ & $142(35.7)$ & $215(54.0)$ & $86(43.7)$ & $112(63.3)$ \\
\hline OR $(95 \% \mathrm{Cl})$ vs insulin & - & 2.11 (1.58 to 2.81$)$ & 1.40 (0.99 to 1.98$)$ & $3.22(2.21$ to 4.69$)$ \\
\hline$P$ value & - & $<0.001$ & 0.060 & $<0.001$ \\
\hline \multicolumn{5}{|l|}{ Persistence } \\
\hline Stay time, days, mean (SD) & $126.0(65.0)$ & $144.7(55.1)$ & $139.5(56.8)$ & $145.6(55.7)$ \\
\hline HR $(95 \% \mathrm{Cl})$ vs insulin & - & $0.68(0.55$ to 0.85$)$ & 0.74 (0.57 to 0.96$)$ & $0.65(0.48$ to 0.87$)$ \\
\hline$P$ value & - & 0.0005 & 0.025 & 0.0038 \\
\hline Log rank $p$ value & - & 0.0003 & 0.081 & 0.0025 \\
\hline Persistent patients, $\mathrm{n}(\%)$ & $211(53.0)$ & $257(64.6)$ & $115(58.4)$ & $118(66.7)$ \\
\hline \multicolumn{5}{|l|}{ Discontinuation } \\
\hline Patients who discontinued, n (\%) & $187(47.0)$ & $141(35.4)$ & $82(41.6)$ & $59(33.3)$ \\
\hline Time to discontinuation, days, ${ }^{*}$ mean (SD) & $65.0(44.5)$ & $80.4(46.5)$ & $82.7(47.0)$ & $76.8(46.9)$ \\
\hline
\end{tabular}

Twice-daily GLP-1 RAs are not assessed in statistical comparisons concerning frequency of administration because few eligible patients were available; however, these patients are included in the cohorts for all GLP-1 RAs.

Bold values indicate significant differences between the OAD(s) or insulin cohort and the respective GLP-1 RA cohort.

Log rank test results showed good consistency with the results of the Cox model.

${ }^{*}$ Time for discontinuation is presented only for patients who discontinued. For the full cohorts, this is presented as stay time.

GLP-1 RA, glucagon-like peptide-1 receptor agonist; OAD, oral antidiabetic drug; OD, once-daily; OW, once-weekly; PDC, proportion of days covered.

CI 1.51 to $6.05 ; \mathrm{p}=0.002)$ than those who intensified with insulin (figure 2D).

\section{Adherence and persistence}

Data on adherence and persistence are shown in table 2 .

\section{GLP-1 RA versus OAD(s)}

Patients receiving a GLP-1 RA were less adherent to treatment than those receiving $\mathrm{OAD}(\mathrm{s})$, with a lower mean PDC and a smaller proportion of patients with PDC $\geq 0.8$ (52.5\% vs $59.1 \%$; OR: 0.76 ; $95 \%$ CI 0.60 to 0.98 ; $\mathrm{p}=0.0032)$. This trend was affected by the frequency of
GLP-1 RA injection: $41.8 \%$ of those receiving once-daily (OD) GLP-1 RAs were adherent to treatment, whereas adherence in those receiving once-weekly (OW) GLP-1 RAs $(61.1 \%)$ was not significantly different from the $\mathrm{OAD}(\mathrm{s})$ cohort.

Stay time was not significantly different between the GLP-1 RA cohort and the OAD(s) cohort (HR: 1.16; 95\% CI 0.94 to $1.42 ; p=0.16)$. A smaller proportion of patients receiving a GLP-1 RA were persistent than those receiving $\mathrm{OAD}(\mathrm{s})(63.8 \%$ vs $67.5 \%)$. Overall, $67.8 \%$ of patients receiving OW GLP-1 RAs and $57.4 \%$ of those receiving OD GLP-1 RAs were persistent. 


\section{GLP-1 RA versus insulin}

Patients receiving a GLP-1 RA were significantly more adherent to treatment than those receiving insulin, with a higher mean PDC and a greater proportion of adherent patients $(54.0 \%$ vs $35.7 \%$; OR: 2.11 ; $95 \%$ CI 1.58 to 2.81; $\mathrm{p}<0.001)$. Administration frequency of GLP-1 RA appeared to affect adherence rates (OW: 63.3\%; OD: $43.7 \%$ ).

Stay time was significantly longer for the GLP-1 RA cohort than the insulin cohort (HR: 0.68 ; 95\% CI 0.55 to $0.85 ; \mathrm{p}<0.001)$, and a greater proportion of patients were persistent with treatment, regardless of administration frequency (all GLP-1 RAs: 64.6\%; OW: 66.7\%; OD: $58.4 \%$ vs insulin: $53.0 \%$ ).

\section{CONCLUSIONS}

This is one of the first real-world, observational studies using EHR combined with claims data to assess multiple options for treatment intensification in type 2 diabetes. By presenting comparative effectiveness evidence on the full range of choices available at this therapeutic decision point, our findings provide valuable guidance to clinicians. Our PS-matched analysis indicates that patients receiving two OADs have a significantly higher chance of reaching $\mathrm{HbA}_{1 c}$ targets and achieving weight loss at 6 months following intensification with GLP-1 RA rather than additional $\mathrm{OAD}(\mathrm{s})$, provided that they had an equal chance of receiving each intensification option. Similar results were observed for patients who were equally likely to intensify treatment with either a GLP-1 RA or insulin. Overall, 33\%-38\% of patients intensifying with a GLP-1 $\mathrm{RA}$ achieved $\mathrm{HbA}_{1 \mathrm{c}}<7 \%$ (53 $\mathrm{mmol} / \mathrm{mol}$ ). This is similar to rates reported in previous observational studies: $21 \%-33 \%$ at 12 months in patients intensifying OAD treatment with GLP-1 RA and basal insulin, ${ }^{13}$ and $30 \%$ in patients adding lixisenatide to basal insulin $( \pm$ OADs $) .{ }^{14}$

Patients in our study receiving a GLP-1 RA rather than $\mathrm{OAD}(\mathrm{s})$ or insulin were more likely to achieve target $\mathrm{HbA}_{1 c}$ without weight gain while discontinuing one or more baseline OADs. For baseline OAD discontinuation as a single endpoint, there was no difference between the GLP-1 RA and insulin cohorts, but patients who intensified treatment with a GLP-1 RA were nearly twice as likely to discontinue a baseline $\mathrm{OAD}$ as those in the $\mathrm{OAD}(\mathrm{s})$ cohort. Although the reasons for this cannot be inferred retrospectively, it is likely that baseline OAD discontinuation in the GLP-1 RA cohorts was partly driven by patients discontinuing DPP-4is, in line with the ADA guidance. ${ }^{4}$

Patients who were adherent to intensification therapy tended to achieve greater $\mathrm{HbA}_{1 \mathrm{c}}$ reduction and weight loss from baseline. Medication-taking behavior was affected by both mode and frequency of administration: GLP-1 RAs were associated with higher adherence and persistence than insulin, but significantly lower adherence than OADs. This difference was partly driven by low adherence and persistence rates with OD rather than OW GLP-1 RAs; another possible explanation is the gastrointestinal side effects that are often linked to early discontinuation in this treatment class. ${ }^{4}$ In future, analyzing adherence and persistence separately during days $0-90$ and days 91-180 after intensification would allow examination of medication-taking behavior in those who persisted with treatment beyond 90 days.

Our use of linked EHR and claims data was a major strength of this study because it provided confirmation that all included patients had received their medication. Consequently, our study was able to mimic specific points in the treatment pathway, providing evidence to complement the results of previous RCTs that have examined treatment intensification for patients receiving two OADs. ${ }^{15}$ Although our approach in assessing GLP-1 RAs as a class rather than individually is limited in its specificity and does not take into account the differences between GLP-1 RAs, it accurately reflects clinical decision-making, whereby treating physicians first identify the most appropriate class of antidiabetic medication before selecting a specific therapy.

Lack of randomization and risk of bias are potential limitations of retrospective observational studies. To mitigate against these, we used PS matching to obtain balanced cohorts and importantly performed exact matching by baseline $\mathrm{HbA}_{1 \mathrm{c}}$ and $\mathrm{BMI}$ categories, resulting in cohorts with identical baseline values and allowing us to detect clinically significant changes at follow-up. Subsequent adjustment of the models used to calculate differences between treatment cohorts was intended to address residual confounding, which was particularly valuable for analyses in subpopulations of the main cohorts. We conducted sensitivity analyses using unadjusted models and obtained results similar to the main analyses; however, it is possible that residual confounding remained. It should be noted that PS matching effectively created two subpopulations: those for whom treatment intensification with either an OAD or a GLP-1 RA is indicated and those whose disease has progressed to the requirement for either a GLP-1 RA or insulin. This is reflected in the higher mean $\mathrm{HbA}_{1 \mathrm{c}}$ in the insulin cohorts before matching, indicating that these patients had more advanced disease than those in the other treatment cohorts. Therefore, our results should be interpreted in the context of these distinct treatment decisions. We also acknowledge that, perhaps due to use of the Explorys database, the mean BMI of patients in our study was slightly higher than might be expected in a general population with type 2 diabetes. Although the separation of $\mathrm{HbA}_{1 \mathrm{c}}$ and weight/composite outcomes cohorts could be considered to limit the generalizability of the results, we show that baseline demographic and disease characteristics were similar across all cohorts, providing relatively high confidence that $\mathrm{HbA}_{1 c}$ and weight benefits are realized in similar patient populations.

Another limitation of claims data is the need to infer some aspects of medication-taking behavior. We selected eligible patients by the presence of relevant treatment claims, with no requirement for continuous treatment 
periods during the baseline period and no restriction by number of days of index medication prescribed. Although this is an established method of patient identification in claims databases and avoids a possible source of selection bias, it meant that some instances of baseline or index treatment discontinuation may have gone undetected. In future, when more eligible patients are available in these databases, sensitivity analyses requiring overlapping treatment periods could be conducted to assess whether this had an impact on our results.

In our PS-matched cohorts from a population receiving two OADs, treatment intensification with a GLP-1 RA provided significant benefits in terms of glycemic control and weight management compared with additional OADs or insulin, respectively. Future analyses including patients receiving newer GLP-1 RAs would be expected to show even greater benefits associated with this treatment class due to their comparatively greater efficacy. Furthermore, the PATHWAY study design and matching methodology will be valuable to compare different treatment intensification options, to examine other points in the treatment pathway, to assess costs and resource use, and to examine how the availability of oral semaglutide might affect future prescribing practices and patient acceptance of GLP-1 RAs.

\section{Author affiliations}

${ }^{1}$ Division of Diabetes, Endocrinology, and Metabolism, Department of Internal Medicine, University of Nebraska Medical Center, Omaha, Nebraska, USA

${ }^{2}$ Novo Nordisk A/S, Søborg, Denmark

${ }^{3}$ Novo Nordisk Global Service Centre India Pvt. Ltd, Bangalore, India

${ }^{4}$ Department of Internal Medicine and Population and Data Sciences, University of Texas Southwestern Medical Center, Dallas, Texas, USA

Acknowledgements The authors acknowledge the medical writing assistance of PharmaGenesis 0xford Central.

Contributors All authors contributed to study design, data interpretation, and writing and critical review of the manuscript. KKM performed the data analysis. ARK is the guarantor of this work and as such had full access to all of the data in the study and takes responsibility for the integrity of the data and the accuracy of the data analysis.

Funding This study was funded by Novo Nordisk A/S.

Competing interests CD has performed consultancy for AstraZeneca, Bayer AG and Novo Nordisk A/S. ARK and MLW are employees of, and shareholders in, Novo Nordisk A/S. KKM is an employee of Novo Nordisk Global Service Centre India, which is part of Novo Nordisk A/S. IL has performed consultancy for AstraZeneca, Boehringer Ingelheim Pharmaceuticals, Eli Lilly and Company, Intarcia Therapeutics, Janssen Pharmaceuticals, MannKind Corporation, Novo Nordisk A/S, Sanofi, TARGET PharmaSolutions and Valeritas.

Patient consent for publication Not required.

Provenance and peer review Not commissioned; externally peer reviewed.

Data availability statement Data supporting the findings of this study are under license from IBM. Aggregate data are available from the authors upon reasonable request.

Supplemental material This content has been supplied by the author(s). It has not been vetted by BMJ Publishing Group Limited (BMJ) and may not have been peer-reviewed. Any opinions or recommendations discussed are solely those of the author(s) and are not endorsed by BMJ. BMJ disclaims all liability and responsibility arising from any reliance placed on the content. Where the content includes any translated material, BMJ does not warrant the accuracy and reliability of the translations (including but not limited to local regulations, clinical guidelines, terminology, drug names and drug dosages), and is not responsible for any error and/or omissions arising from translation and adaptation or otherwise.

Open access This is an open access article distributed in accordance with the Creative Commons Attribution Non Commercial (CC BY-NC 4.0) license, which permits others to distribute, remix, adapt, build upon this work non-commercially, and license their derivative works on different terms, provided the original work is properly cited, appropriate credit is given, any changes made indicated, and the use is non-commercial. See: http://creativecommons.org/licenses/by-nc/4.0/.

\section{ORCID iDs}

Cyrus Desouza http://orcid.org/0000-0001-6660-0568

Ildiko Lingvay http://orcid.org/0000-0001-7006-7401

\section{REFERENCES}

1 ADVANCE Collaborative Group, Patel A, MacMahon S, et al. Intensive blood glucose control and vascular outcomes in patients with type 2 diabetes. N Engl J Med 2008;358:2560-72.

2 Zoungas S, Patel A, Chalmers J, et al. Severe hypoglycemia and risks of vascular events and death. N Engl J Med 2010;363:1410-8.

3 American Diabetes Association. 8. Obesity management for the treatment of type 2 diabetes: standards of medical care in diabetes-2020. Diabetes Care 2020;43:S89-97.

4 American Diabetes Association. 9. Pharmacologic approaches to glycemic treatment: standards of medical care in diabetes-2020. Diabetes Care 2020;43:S98-110.

5 Pantalone KM, Misra-Hebert AD, Hobbs TM, et al. Intensification patterns and the probability of $\mathrm{HbA}_{1 \mathrm{c}}$ goal attainment in Type 2 diabetes mellitus: real-world evidence for the concept of 'intensification inertia'. Diabet Med 2020;37:1114-24.

6 IBM. IBM Explorys cohort discovery, IBM Explorys therapeutic datasets, and IBM Explorys virtual workbench provide life sciences insights into real-world care delivery, 2016. Available: https://www01.ibm.com/common/ssi/ShowDoc.wss?docURL=/common/ssi/ rep_ca/6/872/ENUSAP16-0346/index.html\&request_locale=en [Accessed 31 Jan 2020].

7 IBM Watson Health. White paper: IBM MarketScan research databases for life sciences researchers, 2018. Available: https:// www.ibm.com/downloads/cas/ONKLE57Y [Accessed 12 Feb 2020].

8 ICD. Codes. ICD-9-CM chapters, 2016. Available: https://icd.codes/ icd $9 \mathrm{~cm}$ [Accessed 5 Jun 2020].

9 ICD. Codes. ICD-10-CM chapters, 2016. Available: https://icd. codes/icd10cm [Accessed 5 Jun 2020].

10 Sikka R, Xia F, Aubert RE. Estimating medication persistency using administrative claims data. Am J Manag Care 2005;11:449-57.

11 Austin PC. An introduction to propensity score methods for reducing the effects of confounding in observational studies. Multivariate Behav Res 2011;46:399-424.

12 Nguyen T-L, Collins GS, Spence J, et al. Comparison of the ability of double-robust estimators to correct bias in propensity score matching analysis. A Monte Carlo simulation study. Pharmacoepidemiol Drug Saf 2017;26:1513-9.

13 Peng XV, Ayyagari R, Lubwama R, et al. Impact of simultaneous versus sequential initiation of basal insulin and glucagon-like peptide-1 receptor agonists on HbA1c in type 2 diabetes: a retrospective observational study. Diabetes Ther 2020;11:995-1005.

14 Bellido D, Abellán P, Ruiz Palomar JM, et al. Intensification of basal insulin therapy with lixisenatide in patients with type 2 diabetes in a real-world setting: the BASAL-LIXI study. Curr Ther Res Clin Exp 2018;89:37-42.

15 Lozano-Ortega G, Goring S, Bennett HA, et al. Network metaanalysis of treatments for type 2 diabetes mellitus following failure with metformin plus sulfonylurea. Curr Med Res Opin 2016;32:807-16.

16 Young BA, Lin E, Von Korff M, et al. Diabetes complications severity index and risk of mortality, hospitalization, and healthcare utilization. Am J Manag Care 2008;14:15-23.

17 Quan H, Sundararajan V, Halfon P, et al. Coding algorithms for defining comorbidities in ICD-9-CM and ICD-10 administrative data. Med Care 2005;43:1130-9.

18 Quan $\mathrm{H}$, Li B, Couris CM, et al. Updating and validating the Charlson comorbidity index and score for risk adjustment in hospital discharge Abstracts using data from 6 countries. Am J Epidemiol 2011:173:676-82. 